\title{
Primary Malignant Melanoma of the Lung: A Case Report
} Apostolos Dountsis ${ }^{1}$, Charalambos Zisis*1, Evangelia Karagianni ${ }^{2}$ and Jubrail Dahabreh ${ }^{1}$

Address: ${ }^{1}$ Department of Thoracic Surgery, Athens Medical Center, Athens, Greece and ${ }^{2}$ Department of Pathology, Athens Medical Center, Athens, Greece

Email: Apostolos Dountsis - aduntsis@hol.gr; Charalambos Zisis* - dkakats@cc.uoa.gr; Evangelia Karagianni - evkaragianni@hotmail.com; Jubrail Dahabreh - dachissa@hotmail.com

* Corresponding author

Published: 30 November 2003

World Journal of Surgical Oncology 2003, I:26

This article is available from: http://www.wjso.com/content/l/I/26

(C) 2003 Dountsis et al; licensee BioMed Central Ltd. This is an Open Access article: verbatim copying and redistribution of this article are permitted in all media for any purpose, provided this notice is preserved along with the article's original URL.
Received: 05 August 2003

Accepted: 30 November 2003

\begin{abstract}
Background: Primary melanoma of the lung is an extremely rare pathological entity and sparsely reported in the literature.
\end{abstract}

Case presentation: A case of primary malignant melanoma of the lung in a 41 -year-old female is reported. The clinical, radiological and histopathological features are discussed. The initial symptom was cough, whereas the chest radiography showed a round opacity of the right lung. The computed tomography of the chest revealed a well-demarcated mass lesion in the right upper lobe. Endobronchial mass causing obstruction of the upper lobar bronchus was the bronchoscopic finding. Patient underwent pneumonectomy. A diagnosis of melanoma was confirmed postoperatively after the immunohistochemistry. Primary nature of the tumour in the lung results from the demonstration of characteristic junctional pattern of melanoma cells beneath the bronchial epithelium on histopathology, and from exclusion of other potential primary sites in the clinical, paraclinical and laboratory examination.

Conclusions: Primary melanoma of the lung represents a rare pathological entity. Careful interpretation of histopathological information in correlation with all other findings from clinical and paraclinical studies can establish a diagnosis. Follow-up is necessary in order to diagnose potential dissemination or secondary sites of the disease. Due to the small number of cases reported in the literature, there is no experience on the management and the prognosis of the disease, but surgical resection remains the cornerstone of the treatment.

\section{Introduction}

Malignant melanoma (MM) is a malignant tumour, arising from the pigment producing cells (melanosomes) of the deeper layers of the skin (or the eye) and is the leading cause of death attributable to skin lesions. It is usually described as an irregular dark skin lesion that may have areas of varying colour. The mucosal localizations, such as in the oral cavity, oesophagus, larynx, the ano-genital mucosa, and in ovarian cystic teratoma have been also described. 


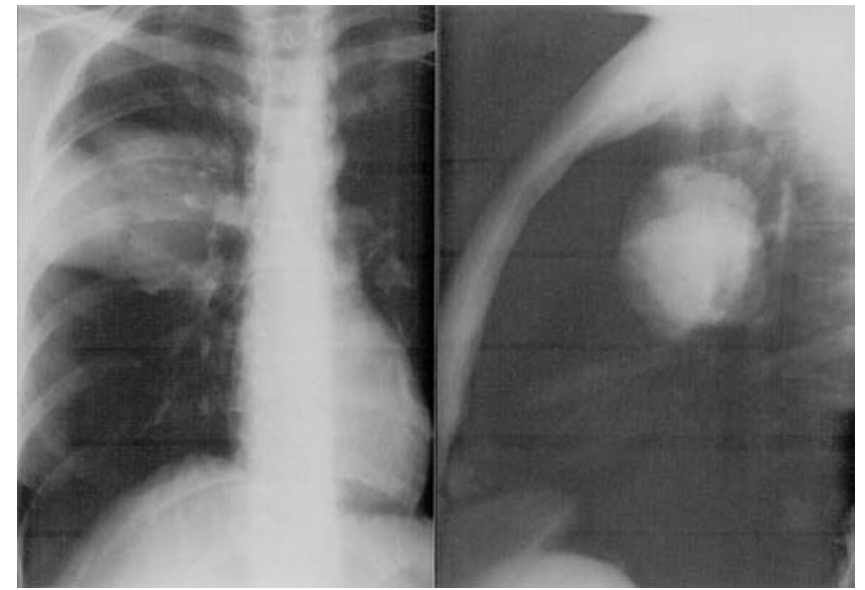

Figure I

Thoracic radiography showing the mass of the right lung.

Primary MM of the lung is an uncommon neoplasm that may be confused with more conventional types of lung cancer. The proposed criteria for diagnosis are often difficult to be fulfilled, and the lesion is characterised by a poor prognosis.

More than 30 cases have been reported in the literature, but not all of them meet the requested criteria. Particularly, an extrapulmonary origin of the tumour has to be excluded before considering this diagnosis, metastasis from an occult primary must be convincingly excluded and the tumour should confirm to laid guidelines [1-4].

The case report seems to fulfil the criteria to be considered in the little group of definite primary melanoma of the lower respiratory tract.

\section{Case Report}

A 41-year-old Greek non-smoker female presented with respiratory symptoms including a cough which did not improve with symptomatic treatment. She gave a past history of tuberculous pleurisy at the age of 11 years.

Chest radiograph showed a round opacity in the right lung (Figure 1) and computed tomography revealed a well-demarcated mass lesion in the right upper lobe extending from the lateral chest wall to the hilum. She was admitted for pneumonectomy with a provisional diagnosis of bronchogenic carcinoma.

No additional abnormalities were observed on subsequent detailed metastatic work-up including computed tomography of brain and abdomen and whole body bone scintigraphy. Bronchoscopy revealed an endobronchial

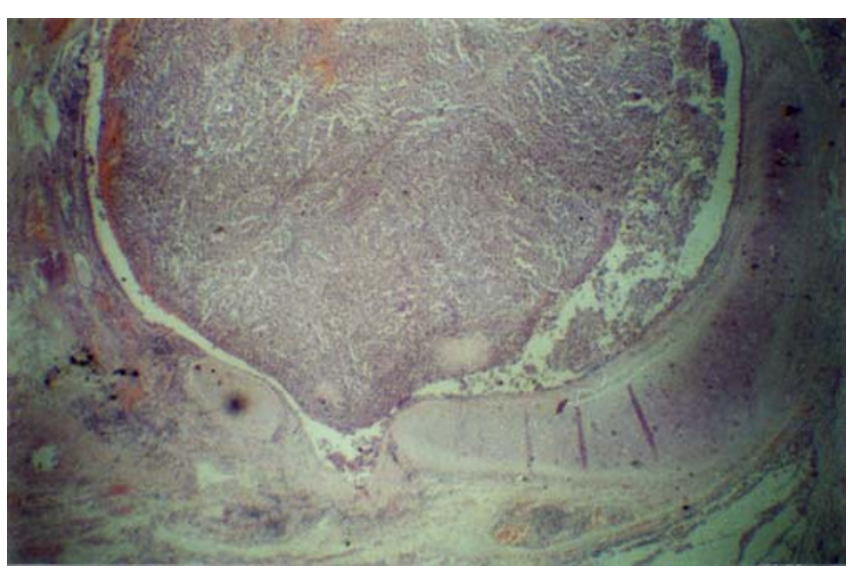

Figure 2

photomicrograph of the polypoidal mass of malignant melanoma showing endobronchial tumor with mucosal invasion. (Hematoxylin-Eosin $\times 50$ ).

mass obstructing right upper lobe bronchus almost totally. Tissue sampling resulted in histopathological diagnosis of non-small-cell lung carcinoma (NSSLC), probably epidermoid. She was submitted to thoracotomy and a solid neoplasm extending from the hilum was found. A pneumonectomy with mediastinal lymph node dissection was carried out.

On gross examination of the resected specimen a darkly pigmented neoplasm with solid growth pattern was seen. The tumour was submucosal and endobronchial with extension into the peribronchial soft tissue. Initial interpretations of gross findings included carcinoid tumour, non-small-cell carcinoma, and MM. Histologically the tumour was composed predominantly of epithelioid tumour cells, junctional change and mitotic activity with characteristic nesting of malignant cells beneath the bronchial epithelium was also seen suggesting a diagnosis of MM (Figure 2). The cells were arranged in alveolar pattern (figure 3). The presence of MM was confirmed by positive immunohistochemichal reaction with antibodies to S-100 protein (Figure 4), and melanoma associated monoclonal antibody HMB45, whereas cytokeratin, CAM 5.2 , and chromogranin were negative. No bronchial in situ component was detected. There were no mediastinal lymph nodes metastases.

Considering the possibility of pulmonary metastasis of malignant melanoma a detailed cutaneous, mucosal and ophthalmic examination was carried out. This failed to show any extrapulmonary disease. A pan endoscopy (colonoscopy; upper gastrointestinal scopy) too failed to detect any other possible primary tumour. Patient was 


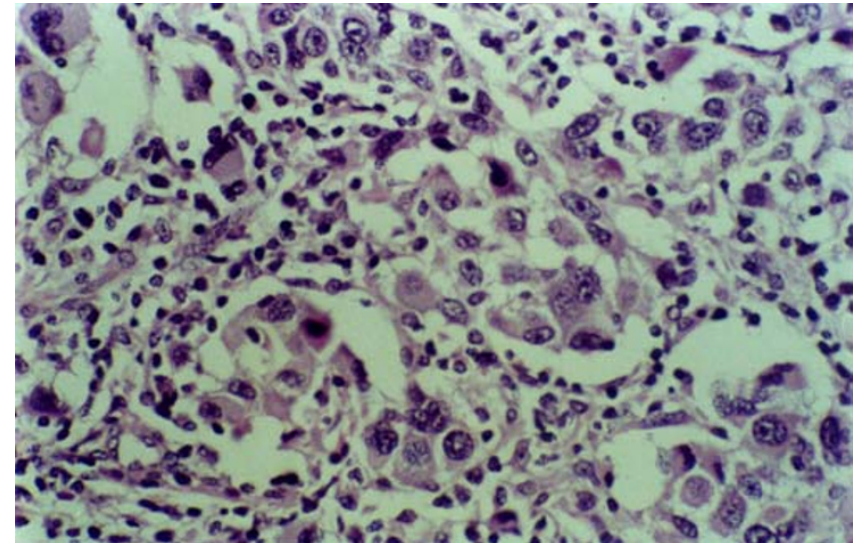

Figure 3

Photomicrograph showing malignant melanoma cells in alveolar pattern (Hematoxylin-Eosin $\times 400$ ).

started on adjuvant $\alpha$-interferon postoperatively for 6 months, and is living disease free for 18 months after the surgery.

\section{Discussion}

Primary MM of the lung is a very rare neoplasm, accounting for $0.01 \%$ of all lung tumours [3]. It is frequently endobronchial and manifest with symptoms of cough, haemoptysis, postobstructive pneumonia, lobar collapse or atelectasis. In 30\% of the cases primary MM of the lung is an incidental finding on chest radiography [4].

These clinical observations pertain to a series of 19 patients reviewed in 1999 with pathology compatible with primary MM of the lung [4].

The clinical and radiological appearance is similar to lung cancer, which is usually the preoperative diagnosis, as in the present case. A preoperative computerised tomographic (CT) guided fine needle aspiration cytology (FNAC) is of help in such situation.

The final diagnosis of a primary MM of the lung is established based on clinical, radiological and pathological findings. The proposed criteria for diagnosis of primary MM include the following [5-7]:

1. Junctional changes like "dropping off" or "nesting" of melanoma cells just beneath the bronchial epithelium.

2. Invasion of the bronchial epithelium by melanoma cells.

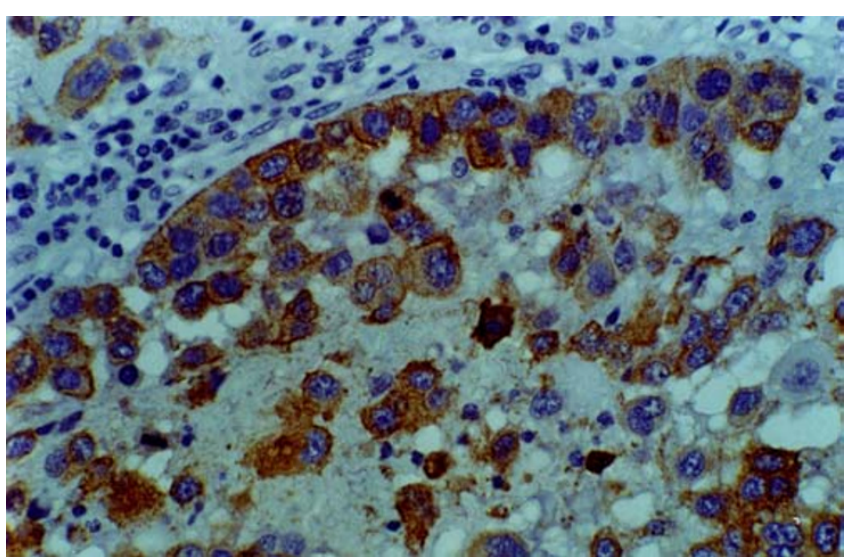

\section{Figure 4}

Photomicrograph showing immunohistochemical staining of melanoma cells with antibody S- 100 (Avidin-Biotin Complex $\times 400)$.

3. Malignant melanoma associated with these epithelial changes.

4. A solitary lung tumour.

5. No history of a cutaneous, mucous membrane or ocular melanoma.

6. Absence of any other detectable tumour at the time of diagnosis.

The present case fulfils the aforementioned diagnostic criteria. The pathogenesis of primary MM of the lung is not understood. There exist several theories to explain its occurrence. One of them hypothesises that melanocytes exist throughout the body as cells of a dispersed neuroendocrine system. Normally, melanocytes migrate to the epidermis and the dermoepidermal junction of the skin, but they may migrate to the visceral during embryogenesis. This has been suggested for the oesophagus and the larynx and may be the case in lung too [1]. The residual primitive melanoblasts, which share a common origin with other melanoblasts located in the trachea, oesophagus, and pharynx, give rise to $\mathrm{MM}$ of the lung $[4,5,8]$. Their origin from neuroectoderm is also said to be a cause for their lower incidence in endodermal epithelium [9]. The other theory emphasizes that melanoma cells may derive from a pluripotent stem cell.

The main differential diagnosis is melanocytic carcinoid tumour, melanotic paraganglioma, melanotic schwannoma and pulmonary metastasis of a malignant melanoma. These tumours can often be excluded by 
histopathological and immunohistochemical staining combined with a good clinical history and examination of the patient [2].

Treatment of choice is surgical resection of the tumour with an oncologically adequate margin, as is lobectomy or pneumonectomy. Furthermore, the central pulmonary position of the lesion is a criterion of inclusion in primary $\mathrm{MM}$ of the lung [3]. It is noteworthy that recurrence manifested in two cases of segmental resection, while lymph node involvement at the time of the operation did not preclude long-term survival.

The role of postoperatively adjuvant chemotherapy or radiotherapy either singly or in combination is not known. Radiotherapy has been tried in mucosal melanoma of the head and neck [9] with disappointing results. Chemotherapy has been used mainly for palliation only [9]. The present case received adjuvant interferon $\alpha$.

The prognosis is rather poor, but existing data are not enough to conclude with conviction. Long-term survival was achieved in two cases in the past $(10$ years and 11 years) after lobectomy and pneumonectomy respectively $[10,11]$. Prompt evaluation and close follow-up of the patient is proposed in order to diagnose metastatic dissemination and to improve outcome.

\section{Conclusions}

Although rare, primary MM of the lung should be considered in the differential diagnosis of primary bronchial tumours of the lung as an extremely rare alternative. Reliable data about clinical behaviour, tumour markers, diagnostic modalities and prognostic factors do not exist because of lack of large series. Most of the reports are of single cases of no more than two cases [3]. Histopathological and clinical criteria have been proposed and should be applied in order to characterize a tumour as primary $\mathrm{MM}$ of the lung.

\section{References}

I. Pomeranz AA, Garlock JH: Primary melanocarcinoma of the esophagus. Ann Surg 1955, I 42:296-30I.

2. Wöckel W, Morresi-Hauf A: Primär bronchiales malignes Melanom. Pathologe 1998, 19:299-304.

3. Wilson RW, Moran CA: Primary melanoma of the lung: a clinicopathologic and immunohistochemical study of eight cases. Am J Surg Pathol 1997, 21:1 I 96-1 202.

4. Ost D, Joseph C, Sogoloff H, Melezes G: Primary pulmonary melanoma: case report and literature review. Mayo Clin Proc 1999, 74:62-6.

5. Allen MS, Drash EC: Primary melanoma of the lung. Cancer 1968, 2I:154-9.

6. Jensen OA, Egedorf J: Primary malignant melanoma of the lung. Scand J Respir Dis 1967, 48: I27-35.

7. Kachhara N, Chitrathara K, Abraham EK, Pandey M: Primary malignant melanoma of the vagina. Singapore J Obstet Gynaecol 2003, 34: II-20.
8. Bagwell SP, Flynn SD, Cox PM, Davison JA: Primary malignant melanoma of the lung. Am Rev Respir Dis 1989, I39: I 1543- I547.

9. Pandey M, Mathew A, Abraham EK, lype MI, Sebastian P, Nair MK: Mucosal melanoma of the upper aerodigestive tract: review of 60 published cases from India. Eur J Cancer Prev 2002, I I :3- 10.

10. Reed RJ III, Kent EM: Solitary pulmonary melanomas: two case reports. J Thorac Cardiovasc Surg 1964, 48:226-231.

II. Reid JD, Mehta VT: Melanoma of the lower respiratory tract. Cancer 1966, 19:627-631.

\section{Publish with Biomed Central and every scientist can read your work free of charge}

"BioMed Central will be the most significant development for disseminating the results of biomedical research in our lifetime. " Sir Paul Nurse, Cancer Research UK

Your research papers will be:

- available free of charge to the entire biomedical community

- peer reviewed and published immediately upon acceptance

- cited in PubMed and archived on PubMed Central

- yours - you keep the copyright

Submit your manuscript here:

http://www.biomedcentral.com/info/publishing_adv.asp 